
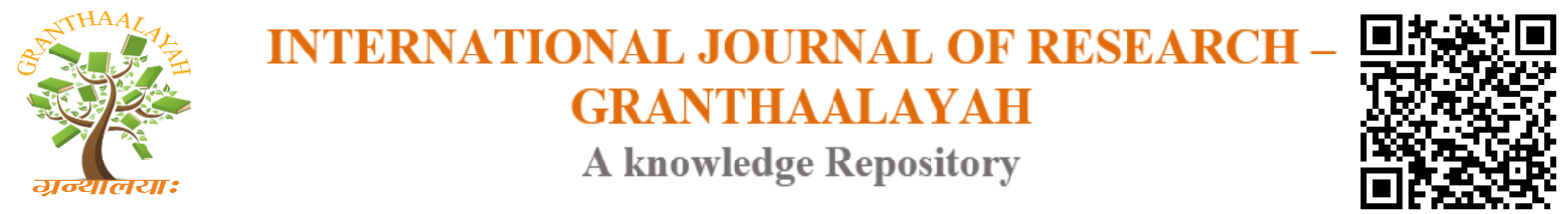

Science

\title{
GLOBAL AND LOCAL DESCRIPTOR FOR CBIR AND IMAGE ENHANCEMENT USING MULTI-FEATURE FUSION METHOD
}

\author{
Devrat Arya ${ }^{* 1}$, Jaimala Jha ${ }^{2}$ \\ ${ }^{* 1}$ Department of CSE/IT, MITS, Gwalior, INDIA \\ ${ }^{2}$ Professor, Department of CSE/IT, MITS, Gwalior, INDIA
}

DOI: https://doi.org/10.29121/granthaalayah.v4.i6.2016.2651

\section{ABSTRACT}

The research is ongoing in CBIR it is getting much popular. In this retrieval of image is done using a technique that searches the necessary features of image. The main work of CBIR is to get retrieve efficient, perfect and fast results. In this algorithm, fused multi-feature for color, texture and figure features. A global and local descriptor (GLD) is proposed in this paper, called Global Correlation Descriptor (GCD) and Discrete Wavelet Transform (DWT), to excerpt color and surface feature respectively so that these features have the same effect in CBIR. In addition, Global Correlation Vector (GCV) and Directional Global Correlation Vector (DGCV) is proposed in this paper which can integrate the advantages of histogram statistics and Color Structure Descriptor (CSD) to characterize color and consistency features respectively. Also, this paper is implemented by Hu moment (HM) for shape feature, it extract 8 moments for image. For the classification process, apply kernel Support vector machine (SVM). The experimental result has computed precision, recall, $f_{-}$measure and execution time. Also, worked on two datasets: Corel-1000 and Soccer-280.

Keywords:

Image retrieval, HSV color space, Global Correlation Vector, DWT, DGVC, SVM.

Cite This Article: Devrat Arya, and Jaimala Jha, "GLOBAL AND LOCAL DESCRIPTOR FOR CBIR AND IMAGE ENHANCEMENT USING MULTI-FEATURE FUSION METHOD” International Journal of Research - Granthaalayah, Vol. 4, No. 6 (2016): 170-182.

\section{INTRODUCTION}

CBIR is a method to search and also index images in the massive set of database based on its visual contents, for example the basis of textures, colors, shapes or spatial layouts in its place of applying tags or various descriptive metadata keywords that might associate with images in database [1]. In traditional CBIR systems work is done through extracting one or extra multidimensional vectors from all image in database, this procedure is complete in a posterior step to start retrieving. At query time, the few vectors are typically extracted from query image and a similarity based function is used then to measure the quantity of variance between different 
images and query image vector in the database. Those images have a similarity vector to query vectors are the set of final retrieved result.

CBIR finds its applications in numerous domains for example medical diagnostics, GIS and military applications, pattern recognition, computer vision and numerous others [2]. However, in most applications CBIR systems are essentially depending on extracting few features, i.e. characteristics that can capture certain visual properties of an image either internationally for the complete image or nearby for its regions [3] [4] and significant features that can efficiently discriminate images and help in matching the most similar ones is the most challenging issue in CBIR systems. Color features are extensively used in CBIR systems as they are independent of image size and orientation [5]. They are typically extracted from various color spaces, e.g. RGB, $\mathrm{HSV}, \mathrm{YCbCr}$, through computing the color histogram, color moments or dominant colors.

\section{METHODS USED IN THIS APPROACH}

\subsection{IMAGE PYRAMID}

The image pyramid is designed on data structure to support effective scaled convolution by decrease image representation. It contains different original copies of an image in sequence with both decrease sample density and resolution in regular steps [6]. Stages of the lower resolution pyramid are achieved themselves by using the highly effective iterative algorithm. The zero or lower level of pyramid $\mathrm{G}_{0}$ is equal to original image.

\subsection{COLOR SPACE AND COLOR QUANTIZATION}

\subsubsection{COLOR SPACE}

Color is natural component and perform necessary role in CBIR systems. The Hue, Saturation and Value (HSV) give the perception representation value according to the human visual feature. The HSV mannequin defines a colour area in terms of range i.e for Hue stages from zero to 360, saturation levels from 0 to a $100 \%$ with vibrancy of colour and it's known as purity. Worth ranges from zero to one $100 \%$ with color brightness[7].

\subsubsection{COLOR QUANTIZATION}

Color quantization is a procedure that decreases various distinct colors used in an image. In this a novel image much visually similar as probable to the original image. For a true color image, the different colors are upto $2^{24}=16777216$, so the color feature extraction from the true color will prompt to a large computation. To reduce the computation without affecting image quality, some color is extracted to represent the image, by this processing speed, improve and reduces the storage space [8]. Several authors reported the effect of color quantization on image retrieval performance [9], with different quantization schemes, like RGB (8X8X8), Lab (4X8X8), HSV (16X4X4), $\mathrm{Lu}^{*} \mathrm{v}^{*}(4 \mathrm{X} 8 \mathrm{X} 8)$. 


\subsection{GLOBAL CORRELATION VECTOR}

Color histogram is general method to extract color feature of an image and has great performance when applied to image recognition. With this technique is to calculate frequency of occurrence of each color[10]. GCV is proposing to extract color feature in image pyramid. The distributions of colors and the spatial correlation between pair of colors can be extracted simultaneously.

\subsection{DISCRETE WAVELET TRANSFORM}

The DWT is based on coding of sub-band, is create to yield a Wavelet Transform fast computation. It is simply to implement and decreases the computation time and resources need. The 2-D DWT of size N1 x N2 of image function $\mathrm{s}(\mathrm{n} 1, \mathrm{n} 2)$ may be expressed as [11]

$$
\begin{aligned}
& W_{\varphi}\left(j_{0}, k_{1}, k_{2}\right)=\frac{1}{\sqrt{N_{1} N_{2}}} \sum_{n_{1}=0}^{N_{1}-1} \sum_{n_{2}=0}^{N_{2}-1} s\left(n_{1}, n_{2}\right) \varphi_{j_{0}, k_{1}, k_{2}}\left(n_{1}, n_{1}\right) \\
& W\left(j_{0}, k_{1}, k_{2}\right)=\frac{1}{\sqrt{N_{1} N_{2}}} \sum_{n_{1}=0}^{N_{1}-1} \sum_{n_{2}=0}^{N_{2}-1} s\left(n_{1}, n_{2}\right) \Psi_{j_{0}, k_{1}, k_{2}}^{i}\left(n_{1}, n_{1}\right)
\end{aligned}
$$

Where $\mathrm{i}=\{\mathrm{H}, \mathrm{V}, \mathrm{D}\}$ indicate the wavelet function direction index. As in 1-D case. $j_{0}$ shows any starting scale, which may be treated as $j_{0}=0$. Above two different equations are 2-D DWT.

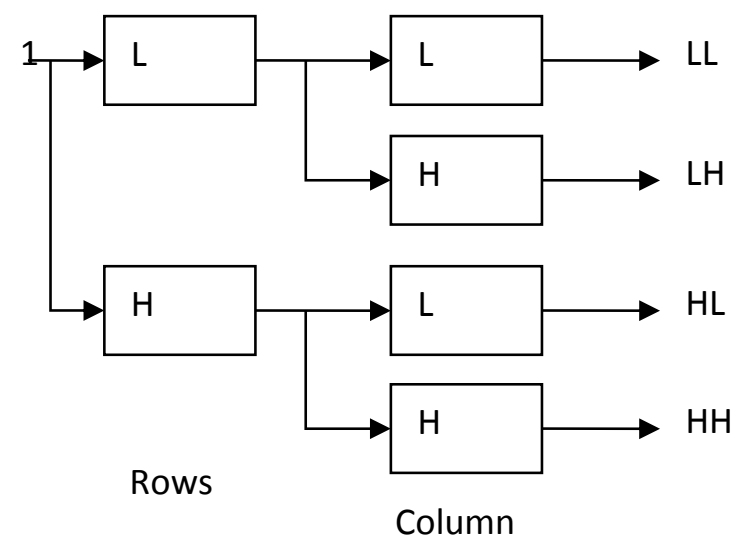

Figure 1: Discrete wavelet sub-band decomposition.

The DWT [6] comparing to other transforms is characteristics of frequency or time used in various application fields. The DWT Sub band flow chart for digital image is present in figure 1, where $\mathrm{L}$ represents to component of low frequency, $\mathrm{H}$ represents to high frequency and the number 1 and 2 represents to decomposition level of the DWT. The sub image LL is element of low frequency, it is the approximate usual image sub image; sub image HL is the component of low frequency in horizontal course and the high in vertical direction, it manifests the longestablished image horizontal side. LH sub image is the factor of high frequency in horizontal course and in vertical direction, it manifests the original image vertical edge; sub image $\mathrm{HH}$ is 
the component of high frequency, it manifests the original image oblique edge. It is present that original image energy is contained in the LL2 low frequency region.

\subsection{DGCV}

In GCV technique the texture features of an image information can be lost directly, so a method called DGVC is proposed to extract texture feature of filtered images. In this technique the two neighbors' text in filtered orientation are considered to compare with the central pixels.

\subsection{SVM}

SVM is a supervised learning approach used in organization and reversion analysis. An SVM training algorithm constructs a model that can classify whether a new sample go down into that category in which the system is trained for the database.

\section{LITERATURE REVIEW}

Xiang-Yang[13] In this paper, a CBIR method has been proposed which uses the combination of Zernike chromaticity distribution moments and rotation-scale invariant Contourlet texture descriptor. The proposed approach outcome yielded bigger retrieval accuracy than different approaches and not using a better function vector dimension. Also the proposed method shows better performance gain in average normal precision, average normal recall, and average retrieval time over the other methods.

Su diptaet.al[14] A novel approach is proposed for texture image retrieval. This approach can be used to overcome the bottleneck of simple distance based image retrieval. The approach is tested using three different databases of varying size, orientation, complexity and number of texture class. Performance of this approach is compared with other promising distance based as well as classifier based retrieval methods.

D. Feng et al.[15] In this paper proposed an efficient indexing technique for CBIR. The proposed technique introduces the ordered quantization to growth distinction among descriptors of quantized feature. Thus, feature point correspondences can be definethrough quantized feature descriptors, and they are used to similarity measure between query image and database image.

\section{PROPOSED METHODOLOGY}

1) Consider color query image 'I' as an N X M size of an image and extract the Red, Green, and Blue Components from an image.

2) Apply adaptive histogram on query image for enhancing the image.

3) Apply image pyramid reduction, initialize kernel center weight to 0.375 for decreasing the size of an image.

$$
I m g_{\text {filtered }}=\sum_{i=1}^{3} B l u r_{-} i m g(I, \text { kernel })
$$


Where $I m g_{\text {filtered }}$ is pyramid reduced image, Blur_img is blurred image, kernel is kernel center weight

4) Apply GCV by assigning 8 levels each to hue, saturation and value provide a quantized HSV space with $8 \times 8 \times 8=512$ histogram bins. And also find color structure descriptor.

5) In the feature extraction process, extract features of an image using DGCV (entropy, energy, homogeneity and contrast).

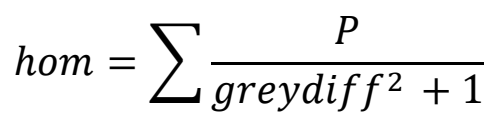

where greydiff $=[0: 1], \mathrm{P}$ is probability function and hom denotes to homogeneity

$$
\text { con }=\sum\left(P X \text { greydiff } f^{2}+1\right)
$$

Where con is contrast of an image

Where eng denotes energy of an image

$$
e n g=\sum(P)^{2}
$$

Where and denotes the entropy of an image

$$
e n t=-\sum P X \log (P+e p s)
$$

$$
B 1=\sum P X g r e y d i f f
$$

Where $\mathrm{B} 1$ is mean value of image

6) Apply Discrete Wavelet Transform at $1^{\text {st }}$ level to get estimated coefficient and vertical, horizontal and diagonal detail coefficients.

7) Calculate moment $(p, q)$ of an image $f(x, y)$ of size $M^{*} N$ is defined using this equation:

where $p$ is the order of $x$ and $q$ is the order of $y$

$$
m_{p, q}=\sum_{x=0}^{M-1} \sum_{y=0}^{N-1} f(x, y) x^{p} y^{q}
$$

8) A central moment is basically the same as the moments just described except that the values of $x$ and $y$ used in the formulas are displaced by the mean values

$$
\beta_{p, q}=\sum_{x=0}^{M-1} \sum_{y=0}^{N-1} f(x, y)\left(x-x_{a v g}\right)^{p}\left(y-y_{a v g}\right)^{q}
$$

Where $x_{\text {avg }}=\frac{m_{10}}{m_{00}}$ and $y_{\text {avg }}=\frac{m_{01}}{m_{00}}$

9) The normalized moments $\gamma_{p, q}$ are the same as the central moments except that they are all divided by an appropriate power of $\mathrm{m}_{00}$ 


$$
\gamma_{p, q}=\frac{\gamma_{p, q}}{m_{00}^{\frac{p+q}{2}+1}}
$$

10) $\mathrm{Hu}$ invariant moments are linear combinations of the central moments and here is how are defined eight $\mathrm{Hu}$ moments:

$$
\begin{aligned}
& I 1= \gamma_{20}+\gamma_{02} \\
& I 2=\left(\gamma_{20}-\gamma_{02}\right)^{\wedge} 2+4 \times \gamma_{11} \\
& I 3=\left(\gamma_{30}-3 \times \gamma_{12}\right)^{\wedge} 2+\left(\gamma_{03}-3 \times \gamma_{21}\right)^{\wedge} 2 \\
& I 4=\left(\gamma_{30}+\gamma_{12}\right)^{\wedge} 2+\left(\gamma_{03}+\gamma_{21}\right)^{\wedge} 2 \\
& I 5=\left(\gamma_{30}-3 \times \gamma_{12}\right) \times\left(\gamma_{30}+\gamma_{12}\right) \times\left(\left(\gamma_{30}+\gamma_{12}\right)^{\wedge} 2-3 \times\left(\gamma_{21}+\gamma_{03}\right)^{\wedge} 2\right)+\left(3 \times \gamma_{21}\right. \\
&\left.\quad-\gamma_{03}\right) \times\left(\gamma_{21}+\gamma_{03}\right) \times\left(3 \times\left(\gamma_{30}+\gamma_{12}\right)^{\wedge} 2-\left(\gamma_{30}+\gamma_{12}\right)^{\wedge} 2\right)
\end{aligned}
$$

11) Repeat step2 to step 9 on a query image within the database.

12) Determine the similarity matrix of query image and image database using Euclidean distance, L1 distance and Weighted L1 distance. We have used Euclidean distance which is the most predictable metric for calculating the lack of involvement between two vectors. Given two vectors $Q$ and T, where

Where

$$
\mathrm{d}(\mathrm{Q}, \mathrm{T})=\sum_{\mathrm{m}} \sum_{\mathrm{n}} \mathrm{d}_{\mathrm{mn}}(\mathrm{Q}, \mathrm{T})
$$

$$
\mathrm{d}_{\mathrm{mn}}=\frac{\left|\left(\mu_{\mathrm{mn}}^{\mathrm{Q}}-\mu_{\mathrm{mn}}^{\mathrm{T}}\right)\right|}{\left|\mu_{\mathrm{mn}}^{\mathrm{Q}}\right|+\left|\mu_{\mathrm{mn}}^{\mathrm{T}}\right|}+\frac{\left|\left(\mu_{\mathrm{mn}}^{\mathrm{Q}}-\mu_{\mathrm{mn}}^{\mathrm{T}}\right)\right|}{\left|\mu_{\mathrm{mn}}^{\mathrm{Q}}\right|+\left|\mu_{\mathrm{mn}}^{\mathrm{T}}\right|}
$$

13) Repeat the steps from 2 to 9 for all the images in the database.

14) Classify the images using SVM classifier and combine global and local features.

$$
\mathrm{f}_{\mathrm{QUERY}}=(\mathrm{fG}, \mathrm{fL})
$$

15) Calculate precision, f-measure, execution time and recall of retrieved images.

$$
\begin{aligned}
& \text { Precision }=\frac{\text { No. of relevant image retrieved }}{\text { Total number of image retrieved }} \\
& \text { Recall }=\frac{\text { No. of relevant image retrieved }}{\text { numberofimage in the datebese }} \\
& F_{\text {measure }}=2 \times \frac{\text { Precision } \times \text { Recall }}{\text { Precision }+ \text { Recall }}
\end{aligned}
$$




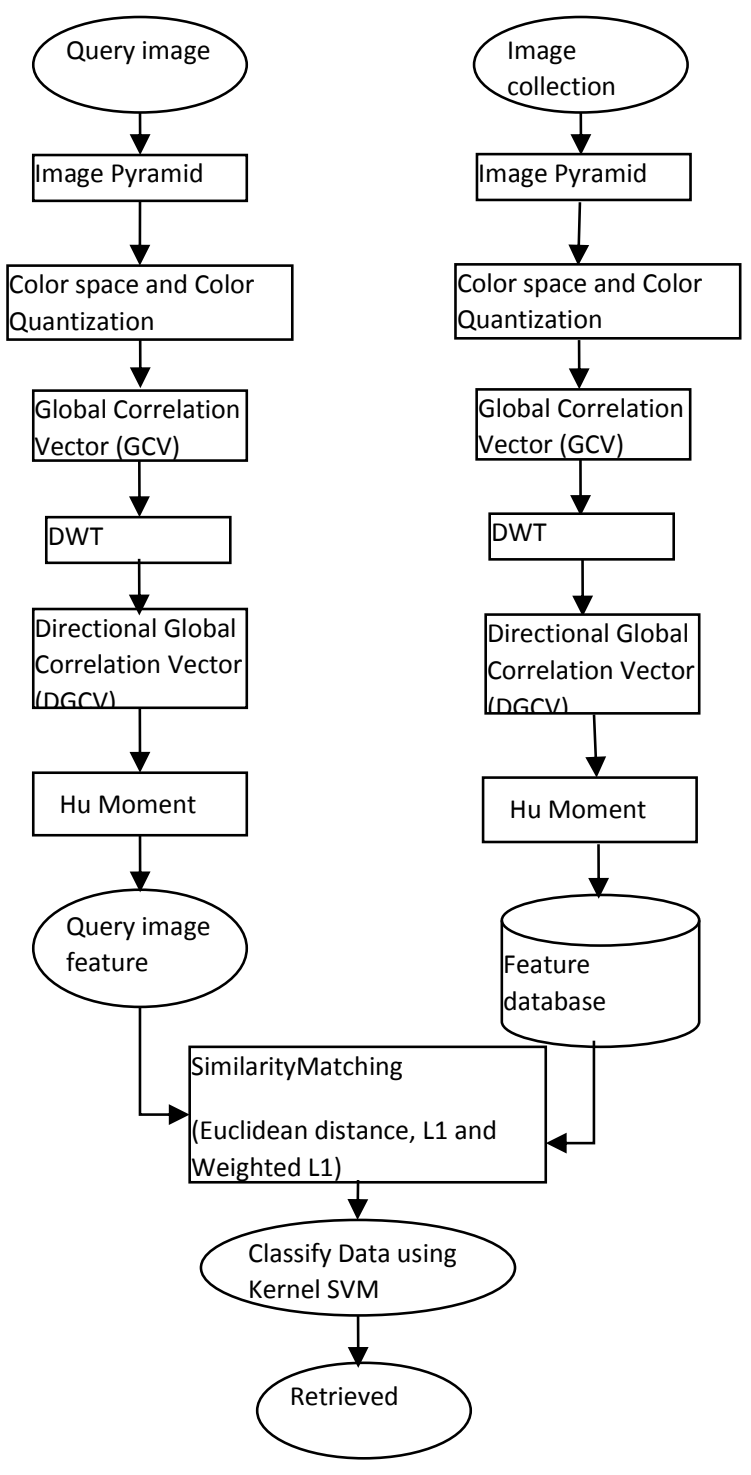

Figure 2: Block diagram of proposed approaches

\section{RESULT ANALYSIS}

We choose the other two datasets, namely Corel-1000 and Soccer-280, to compare GLD with these image feature descriptors. There are 8 images chosen randomly for each category as query images in the Corel dataset and 7 images from Soccer dataset. Graph1 show the experimental results of comparison among GLD and the other descriptor in these datasets. It can be seen that the GLD algorithm have better performance than previous algorithm. 

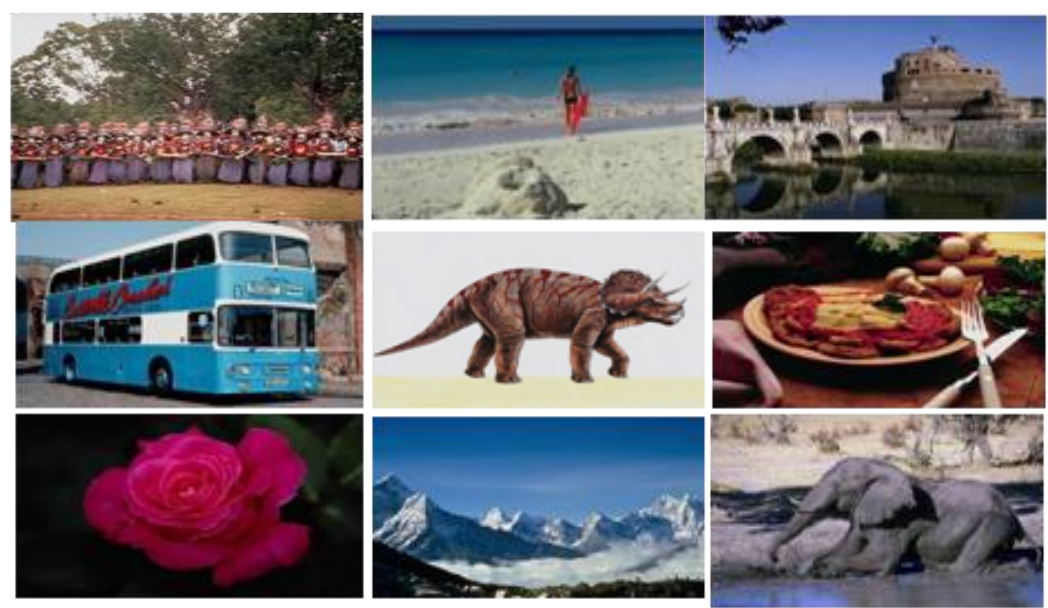

Figure 3: Corel -1000 Dataset

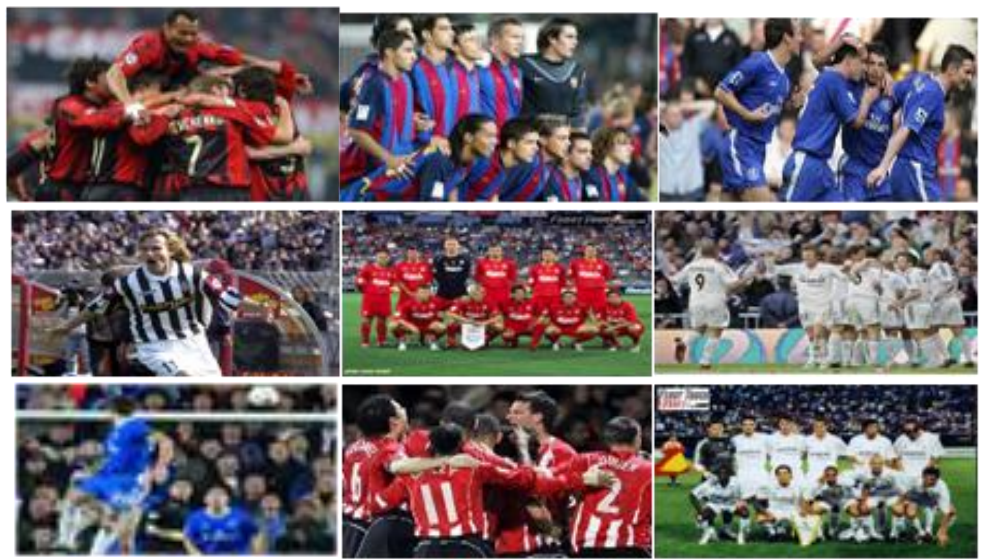

Figure 4: Soccer-280 Dataset

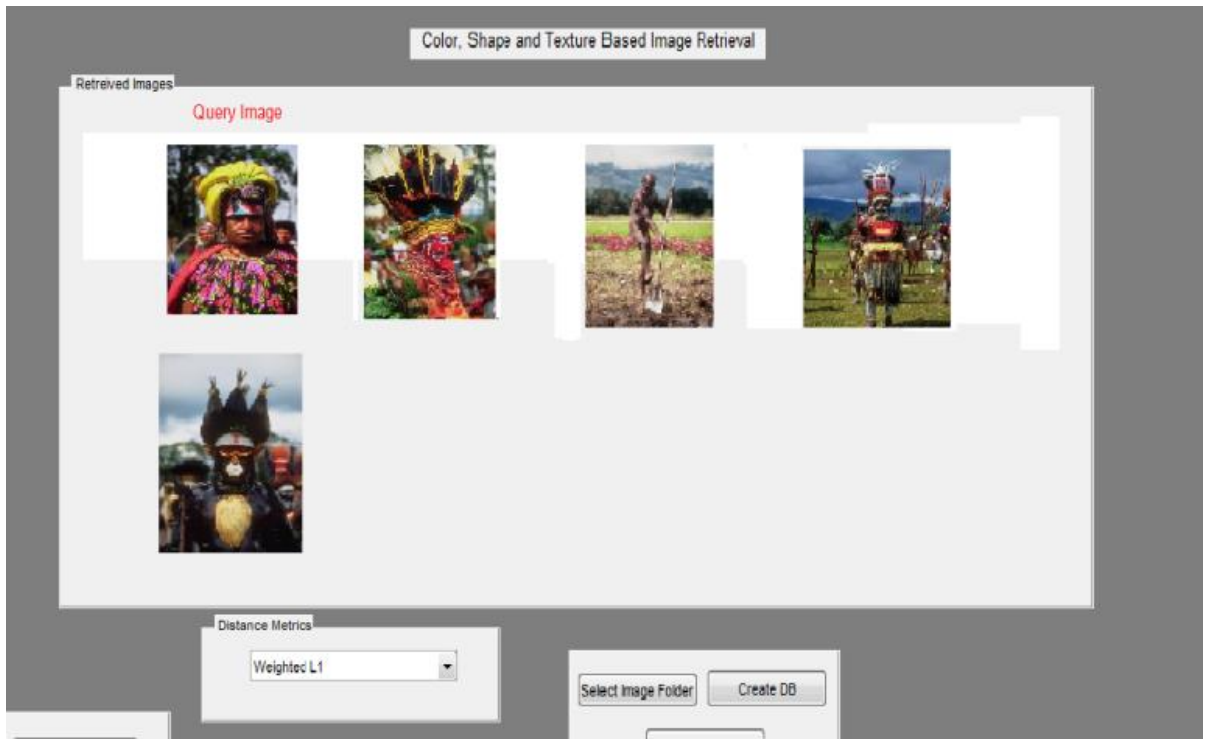

Figure 5: Retrieval result on African Dataset 


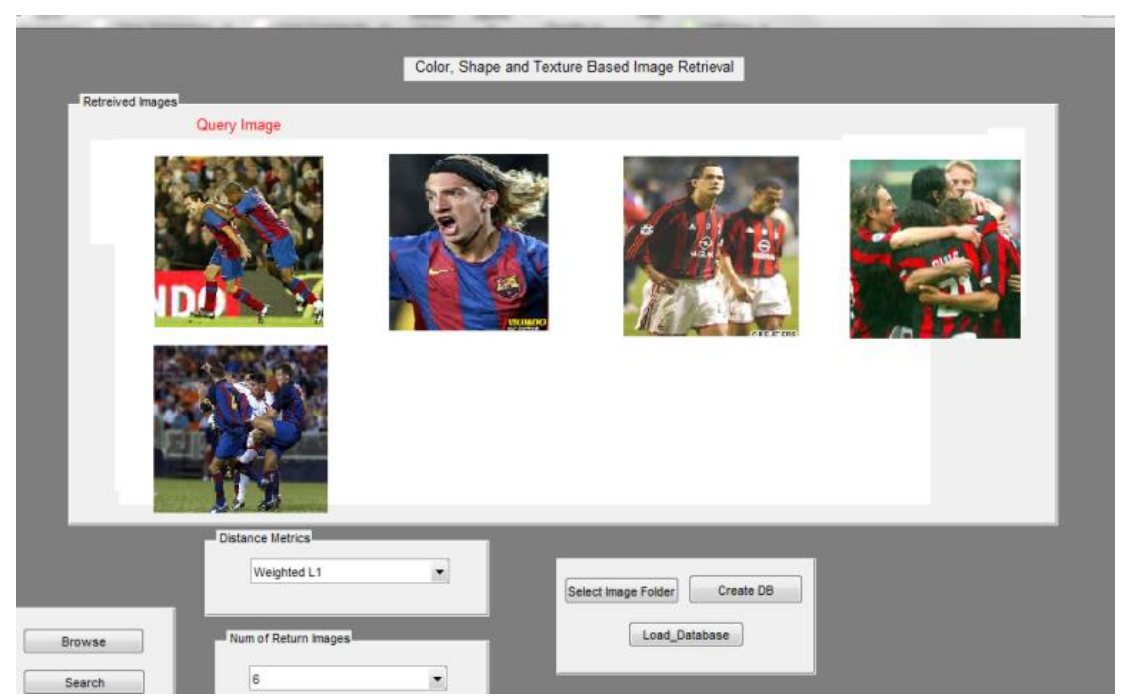

Figure 6: Retrieval results on Soccer data set

The performance of retrieval system can be measured in terms of its recall and precision. Don't forget measure the method capacity to retrieve every the units which can be central, whilst precision measures the approach potential to retrieve only models which can be valuable.

Table 1: Shows base and proposed result on precision and recall for different images

\begin{tabular}{|l|l|l|l|l|}
\hline Category & $\begin{array}{l}\text { Base } \\
\text { Precision } \\
(\%)\end{array}$ & $\begin{array}{l}\text { Proposed } \\
\text { Precision } \\
(\%)\end{array}$ & $\begin{array}{l}\text { Base } \\
\text { Recall } \\
(\%)\end{array}$ & $\begin{array}{l}\text { Proposed } \\
\text { Recall } \\
(\%)\end{array}$ \\
\hline $\begin{array}{l}\text { African } \\
\text { 1.jpg }\end{array}$ & 82.05 & 91.17 & 64 & 62 \\
\hline $\begin{array}{l}\text { Beach } \\
\text { 123.jpg }\end{array}$ & 71.05 & 83.33 & 54 & 70 \\
\hline $\begin{array}{l}\text { Building } \\
\text { 222.jpg }\end{array}$ & 72.97 & 77.41 & 54 & 48 \\
\hline $\begin{array}{l}\text { Bus } \\
\text { 343.jpg }\end{array}$ & 73.33 & 82.85 & 66 & 58 \\
\hline $\begin{array}{l}\text { Elephant } \\
\text { 511.jpg }\end{array}$ & 80 & 85.71 & 56 & 60 \\
\hline $\begin{array}{l}\text { Flower } \\
\text { 634.jpg }\end{array}$ & 78.95 & 86.48 & 60 & 64 \\
\hline $\begin{array}{l}\text { Mountain } \\
\text { 804.jpg }\end{array}$ & 78.26 & 87.50 & 72 & 70 \\
\hline $\begin{array}{l}\text { Food } \\
\text { 991.jpg }\end{array}$ & 77.42 & 80 & 48 & 64 \\
\hline
\end{tabular}

In Table 1 compare the precision and Recall of Base and Proposed work for Corel-1000 dataset. The Precision of Base has reached upto $82.05 \%$ whereas the proposed is $91.17 \%$. 
Table 2: Shows base [10] and proposed result on F-measure and Time for different images

\begin{tabular}{|l|l|l|l|l|}
\hline Category & $\begin{array}{l}\text { Base F- } \\
\text { measure }\end{array}$ & $\begin{array}{l}\text { Proposed } \\
\text { F- } \\
\text { measure }\end{array}$ & $\begin{array}{l}\text { Base } \\
\text { Time }\end{array}$ & $\begin{array}{l}\text { Proposed } \\
\text { Time }\end{array}$ \\
\hline $\begin{array}{l}\text { African } \\
\text { 1.jpg }\end{array}$ & 0.26 & 0.28 & 3.58 & 2.92 \\
\hline Beach & 0.21 & 0.26 & 2.78 & 2.67 \\
\hline Building & 0.20 & 0.27 & 2.92 & 2.61 \\
\hline Bus & 0.25 & 0.26 & 2.78 & 2.60 \\
\hline Elephant & 0.21 & 0.22 & 2.82 & 2.61 \\
\hline Flower & 0.241 & 0.24 & 2.84 & 2.78 \\
\hline Mountain & 0.26 & 0.27 & 2.75 & 2.61 \\
\hline Food & 0.18 & 0.25 & 2.82 & 2.61 \\
\hline
\end{tabular}

In Table 2 compare the F_measure and Time of Base and Proposed work for Corel-1000 dataset. The F_measure of Base has reached upto 0.26 whereas the proposed is 0.27. Time is also decreased as compared to previous algorithm.

Table 3: Shows base [10] Precision result on Similarity measure

\begin{tabular}{|l|l|l|l|l|l|}
\hline \multirow{2}{*}{$\begin{array}{l}\text { Similarity } \\
\text { Measure }\end{array}$} & \multicolumn{5}{|l|}{ Base Precsion (\%) } \\
\cline { 2 - 6 } & 10 & 15 & 20 & 25 & 30 \\
\hline L1 & 73.17 & 74.19 & 68.75 & 75.56 & 66.67 \\
\hline Euclidean & 88.24 & 73.91 & 75 & 81.58 & 66.67 \\
\hline $\begin{array}{l}\text { Weighted } \\
\text { L1 }\end{array}$ & 70.73 & 77.14 & 66.67 & 68.75 & 67.50 \\
\hline
\end{tabular}

Table 3 to Table 6.compare the precision and recall between Base and Proposed system, the total number of the retrieved images are fix from 10 to 30 in the experiments. It can be seen that the L1 distance performs better than other similarity measures and it is much more computationally efficient. Euclidean distance is typically used similarity measures, but now not normally the quality one considering the fact that the distances put too much emphasis on features which are generally distinctive. Weighted L1 distance can be considered as a weighted L1 distance with different weights.

Table 4: Shows Proposed Precision result on Similarity measure

\begin{tabular}{|l|l|l|l|l|l|}
\hline \multirow{2}{*}{$\begin{array}{l}\text { Similarity } \\
\text { Measure }\end{array}$} & \multicolumn{5}{|l|}{ Proposed Precision (\%) } \\
\cline { 2 - 6 } & 10 & 15 & 20 & 25 & 30 \\
\hline L1 & 81.57 & 90 & 76.47 & 80.55 & 82.92 \\
\hline Euclidean & 92.59 & 80.48 & 77.77 & 84.37 & 84.84 \\
\hline $\begin{array}{l}\text { Weighted } \\
\text { L1 }\end{array}$ & 79.06 & 78.78 & 83.33 & 75.60 & 78.37 \\
\hline
\end{tabular}


Table 5: Shows Base Recall result on Similarity measure

\begin{tabular}{|l|l|l|l|l|l|}
\hline Similarity & \multicolumn{6}{|l|}{ Base Recall (\%) } \\
\cline { 2 - 6 } Measure & 10 & 15 & 20 & 25 & 30 \\
\hline L1 & 60 & 46 & 66 & 68 & 68 \\
\hline Euclidean & 60 & 68 & 60 & 62 & 60 \\
\hline $\begin{array}{l}\text { Weighted } \\
\text { L1 }\end{array}$ & 58 & 54 & 72 & 66 & 60 \\
\hline
\end{tabular}

Table 6: Shows Proposed Recall result on Similarity measure

\begin{tabular}{|l|l|l|l|l|l|}
\hline \multirow{2}{*}{$\begin{array}{l}\text { Similarity } \\
\text { Measure }\end{array}$} & \multicolumn{6}{|c|}{ Proposed Recall (\%) } \\
\cline { 2 - 6 } & 10 & 15 & 20 & 25 & 30 \\
\hline L1 & 62 & 54 & 52 & 58 & 68 \\
\hline Euclidean & 50 & 66 & 70 & 54 & 56 \\
\hline $\begin{array}{l}\text { Weighted } \\
\text { L1 }\end{array}$ & 68 & 52 & 50 & 62 & 58 \\
\hline
\end{tabular}

Table 7: Shows Proposed result on F-measure and Time for Soccer dataset on each category

\begin{tabular}{|l|l|l|}
\hline Category & $\begin{array}{l}\text { Proposed } \\
\text { Time }\end{array}$ & $\begin{array}{l}\text { Proposed } \\
\text { Precison } \\
(\%)\end{array}$ \\
\hline Acmilan & 0.42 & 20.83 \\
\hline Barcelona & 0.45 & 33.33 \\
\hline Chelsea & 0.44 & 23.33 \\
\hline Juventus & 0.447 & 50 \\
\hline Liverpool & 0.455 & 40 \\
\hline Madrid & 0.445 & 38.88 \\
\hline Psv & 0.47 & 36.36 \\
\hline
\end{tabular}

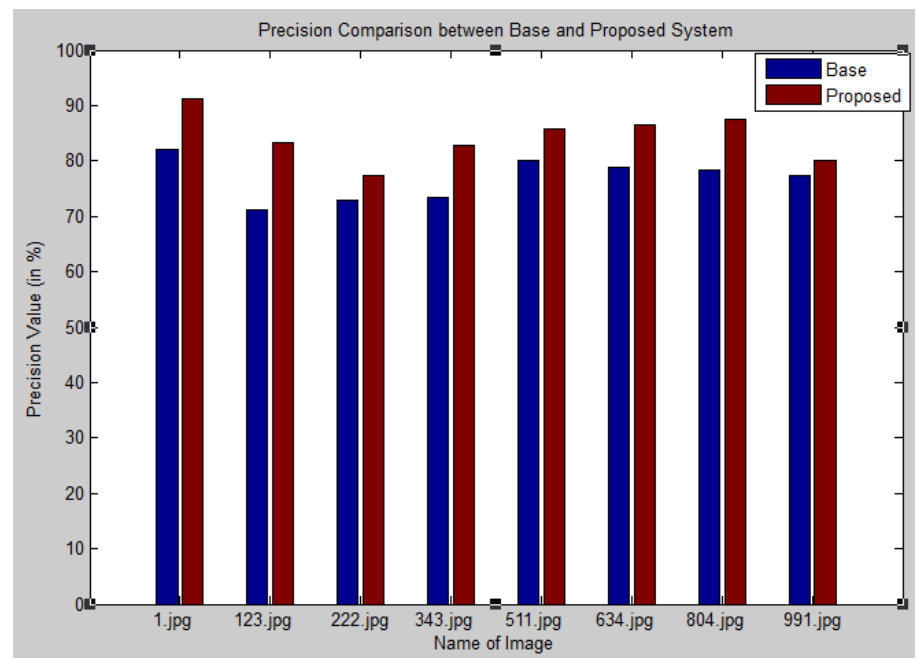

Graph 1: Comparison of Precision between base and Proposed Approach 


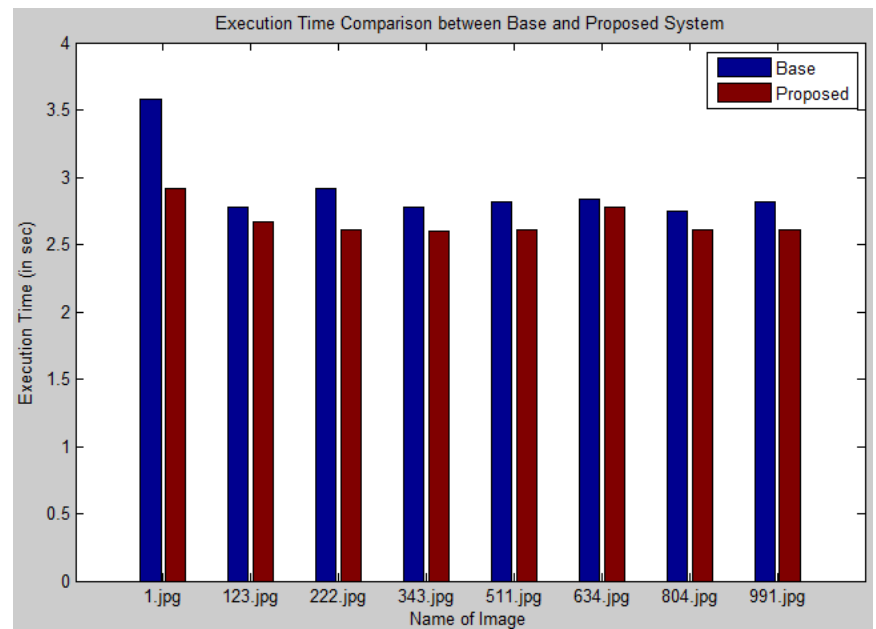

Graph 2: Comparison of Execution time between base and proposed System

\section{CONCLUSION}

On the basis of previous researches, the paper explored low-level features of shape, color and texture extraction of CBIR. After matching the CBIR founded on the shape, color and texture categories with that of the texture and color fused features, it is observed results of shape, color and texture fused categories are more robust than the texture and color features based image recovery. The investigational results have demonstrated that the DGCV algorithm is much more robust and discriminative than other image descriptors in CBIR. The investigational results show good precision upto $91.17 \%$ as matched to previous techniques. Furthermore, work on Soccer dataset for improving precision and recall, increase dataset images for enhance effectiveness of the system.

\section{REFERENCES}

[1] Jain, R. and Krishna, K. (2012) An Approach for Color Based Image Retrieval. International Journal of Advanced Electronics and Communication Systems, 2, Paper ID: 10891. http://techniche-edu.in/journals/index.php/ijaecs/article/view/36/29

[2] Roy, K. and Mukherjee, J. (2013) Image Similarity Measure Using Color Histogram, Color Coherence Vector, and Sobel Method. International Journal of Science and Research (IJSR), 2, 538-543. http://ijsr.net/archive/v2i1/IJSRON2013311.pdf

[3] Selvarajah, S. and Kodituwakku, S.R. (2011) Analysis and Comparison of Texture Features for Content Based Image Retrieval. International Journal of Latest Trends in Computing, 2, 108-113.

[4] Kodituwakku, S.R. and Selvarajah, S. (2010) Comparison of Color Features for Image Retrieval. Indian Journal of Computer Science and Engineering, 1, 207-211.

[5] Mangijao Singha, M. and Hemachandran, K. (2012) Content-Based Image Retrieval Using Color Moment and Gabor Texture Feature. International Journal of Computer Science Issues (IJCSI), 9, 299-309

[6] E. H. Adelson, C. H. Anderson, J. R. Bergen, P. J. Burt, J. M. Ogden "Pyramid methods in image processing" RCA Engineer •29-6 • Nov/Dec 1984. 
[7] Simardeep Kaur and Dr. Vijay Kumar Banga "Content Based Image Retrieval: Survey and Comparison between RGB and HSV model" International Journal of Engineering Trends and Technology (IJETT) - Volume4Issue4-April 2013.

[8] Hafner, J and Sawhney, H. S. - 1995 -. Efficient color histogram indexing for quadratic form distance functions. In IEEE Transactions on Pattern Analysis and Machine Intelligence, Intelligence, 17(7): pp.729- 736.

[9] S.Niranjanan S.P.Raja Gopalan "Performance Efficiency of Quantization using HSV Colour Space and Intersection Distance in CBIR" International Journal of Computer Applications (0975 - 8887) Volume 42-No.21, March 2012.

[10] Lin Feng, Jun Wu, Shenglan Liu, Hongwei Zhang "Global Correlation Descriptor: a novel imagerepresentation for image retrieval" (2015)http://dx.doi.org/10.1016/j.jvcir.2015.09.002

[11] Mohankumar C, Madhavan J "Content Based Image Retrieval Using 2-D Discrete Wavelet with Texture Feature with Different Classifiers" IOSR Journal of Electronics and Communication Engineering (IOSR-JECE).Volume 9, Issue 2, Ver. IV (Mar - Apr. 2014), PP 01-07.

[12] Sumiti Bansal Er. Rishamjot Kaur "A Review on Content Based Image Retrieval using SVM " International Journal of Advanced Research in Computer Science and Software Engineering Volume 4, Issue 7, July 2014.

[13] Xiang-Yang Wang, Hong-Ying Yang, Dong-Ming Li "A new content-based image retrieval technique using color and texture information" Computers and Electrical Engineering Elsevier (2013).

[14] SudiptaMukhopadhyayJatindra Kumar Dash Rahul Das Gupta "Content-based texture image retrieval using fuzzy class membership” Pattern Recognition Letters 34Elsevier (2013) 646-654.

[15] Deying Feng,JieYang n, CongxinLiu "An efficient indexing method for content-based image retrieval” Neurocomputing 106 Elsevier(2013) 103-114

[16] Jaimala Jha Dr. Sarita Sign Bhaduaria "Review of Various Shape Measures for Image Content Based Retrieval" International Journal of Computer \& Communication Engineering Research Nov.2015.

[17] Jaimala Jha Dr. Sarita Singh Bhaduaria" performance based analysis of CBIR methods "International journal of 10 april 2016

[18] Jaimala Jha "Face Detection System Using Adaptive SMQT Feature \& Neural Network Classifier” CCITA -2010 International Conference at Coimbatore,Tamilnadu 2010.

[19] Devbrat Arya, Prof. Jaimala Jha, "A Review On Content Based Image Retrieval Using Feature Extraction” International journal of Advance Research in Comprter Science and Software Engineering (IJARCSSE) Vol. 6 Issue-3 March 2016. ISSN- 2277128.

[20] Hemlata Arya, Jaimala Jha, "Optical water marking for defocused images using 5-Level Transform of DWT and SVD” International Journal for Science \& Advance Research in Technology(IJSART) Vol. 1 Issue-8 ISSN-2395-1052. 